\title{
CONTRIBUIÇÕES DA ESCRITA REFLEXIVA PARA A FORMAÇÃO DOCENTE NO CONTEXTO DA RESIDÊNCIA PEDAGÓGICA DE LÍNGUA INGLESA
}

\author{
Miliane Moreira Cardoso Vieira ${ }^{1}$ \\ Ana Maria Sousa Araújo²
}

\begin{abstract}
RESUMO: O trabalho a seguir traz como tema de estudo o Programa Residência Pedagógica de Língua Inglesa. Objetivamos realizar uma análise autorreflexiva dos relatórios de residência, evidenciando as contribuições da escrita reflexiva desenvolvida durante o programa e das ações oriundas deste para a formação docente. É uma pesquisa documental de cunho qualitativo, cujo estudo está inserido no campo da Linguística Aplicada. Como resultado, concluímos que a escrita reflexiva no contexto da Residência Pedagógica de Língua Inglesa tem grande relevância na formação docente. Em suma, a partir da autorreflexão pudemos ampliar a visão sobre a importância de ações voltadas para a formação de professores, bem como aprimorar as habilidades como futura professora de Língua Inglesa.
\end{abstract}

Palavras-chave: Residência Pedagógica. Língua Inglesa. Autorreflexão.

ABSTRACT: The following work presents the English Language Pedagogical Residency Program as a subject of study. We aim to perform out a self-reflective analysis of the residency reports, highlighting the contributions of reflective writing developed during the program and the actions arising from it for teacher education. It is a qualitative documentary research, whose study is inserted in the field of Applied Linguistics. As a result, we conclude that reflective writing in the context of the English Language Pedagogical Residency has great relevance in teacher education. In short, from self-reflection I was able to broaden the view about the importance of actions aimed at teacher education, as well as improving the skills as a future English language teacher.

Key words: Pedagogical Residency. English Language. Self-reflection.

\section{Introdução}

O presente trabalho tem como tema de investigação o Programa Residência Pedagógica (PRP) da Universidade Federal do Tocantins (UFT). Trata-se de um programa implementado pela Coordenação de Aperfeiçoamento de Pessoal de Nível Superior (CAPES), com o propósito de atender aos objetivos da Política Nacional de Formação de Professores da Educação Básica do Ministério da Educação. O programa foi realizado mediante parceria com as redes públicas de educação básica e objetivou promover projetos inovadores que estimulassem a articulação entre teoria e prática nos cursos de licenciatura.

\footnotetext{
${ }^{1}$ Docente do curso de Pós-graduação do PROFLETRAS (UFNT). Orientadora do Programa de Residência Pedagógica 2018-2020 - UFT/Araguaína/TO. E-mail: milianevieira@mail.uft.edu.br

2 Acadêmica do curso de Letras/Língua Inglesa, residente do Programa de Residência Pedagógica 2018-2020 UFT/Araguaína. E-mail: anamariasouara18@mail.uft.edu.br
} 
O interesse pelo tema surgiu após minha ${ }^{3}$ adesão ao programa, estímulo esse que aumentou durante as escritas dos relatórios como atividades finais do PRP. Desse modo, a partir da releitura dos meus relatórios, percebi a necessidade de desenvolver um trabalho voltado para a autorreflexão, especificamente no contexto do PRP. Assim, nesta pesquisa, objetivamos realizar uma análise autorreflexiva dos relatórios de residência, evidenciando as contribuições da escrita reflexiva desenvolvida durante o programa e das ações oriundas deste para a formação docente.

O PRP, no âmbito da UFT, iniciou-se no dia 6 de agosto de 2018, sendo finalizado no dia 31 de janeiro de 2020. O programa foi dividido em 10 subprojetos com seus respectivos núcleos, os quais corresponderam aos cursos de licenciatura da UFT. Todavia, este trabalho foi desenvolvido a partir do núcleo de Língua Inglesa, e para se referir ao mesmo usaremos o termo Programa de Residência Pedagógica de Língua Inglesa (PRPLI). Para tal investigação, considerando minha posição enquanto futura professora/regente de Língua Inglesa (LI), é indispensável referenciarmos o que as orientações curriculares nacionais ressaltam sobre a relevância desse aprendizado.

Sobre a aprendizagem de uma Língua Estrangeira, os Parâmetros Curriculares Nacionais do Ensino Fundamental II destacam a aprendizagem de LI como essencial na formação integral do indivíduo. Os PCN salientam que a LI contribui para a construção da cidadania, do autodiscernimento e do aperfeiçoamento de consciência cultural da própria Língua.

\begin{abstract}
A aprendizagem de Língua Estrangeira contribui para o processo educacional como um todo, indo muito além da aquisição de um conjunto de habilidades linguísticas. Leva a uma nova percepção da natureza da linguagem, aumenta a compreensão de como a linguagem funciona e desenvolve maior consciência do funcionamento da própria língua materna. (BRASIL, PCN, 2000, p. 37)
\end{abstract}

Assim, por meio do ensino e aprendizado da LI, o indivíduo passa a desenvolver valores pela sua própria cultura, e também desenvolve competências que lhe possibilitam a compreensão discursiva para a produção de sentidos no mundo social.

\footnotetext{
A aprendizagem de Língua Estrangeira representa outra possibilidade de se agir no mundo pelo discurso além daquela que a língua materna oferece. Da mesma forma que o ensino da língua materna, o ensino de Língua Estrangeira incorpora a questão de como as pessoas agem na sociedade por meio da palavra, construindo o mundo social, a si mesmos e os outros à sua volta. Portanto, o ensino de línguas oferece um
}

\footnotetext{
$3 \mathrm{O}$ texto deste trabalho apresenta uma autorreflexão da residente/futura professora, por esta razão há o uso de $1^{\mathrm{a}}$ pessoa do singular em várias partes do texto, no entanto, a pesquisa foi um processo em que ambas estiveram envolvidas.
} 
modo singular para tratar das relações entre a linguagem e o mundo social, já que é o próprio discurso que constrói o mundo social. (BRASIL, PCN, 2000, p. 43)

Nessa perspectiva, a relação entre linguagem e sociedade revelada através da prática social em determinados contextos da LI permite que o indivíduo possa aprimorar seu conhecimento de mundo, como também lidar com questões sociais (trabalho, política, cidadania, saúde e educação). Portanto, em razão das necessidades sociais, intelectuais e profissionais, a LI desempenha um papel formativo relevante no sistema de educação e seu aprendizado não deve ser pensando como uma experiência frustrante, mas de que a Língua Estrangeira possa ser de fato aprendida na escola (BRASIL, PCN, 2000).

Nesse sentido, as ações voltadas para a Formação de Professores têm sido cada vez mais significativas, tendo em vista que ao nos prepararmos melhor como futuros professores da educação básica, poderemos melhorar a qualidade de ensino. Atualmente, a UFT está na segunda proposta do PRP, no entanto, a disciplina de Língua Inglesa não foi selecionada como disciplina essencial pela CAPES. Portanto, o desenvolvimento deste trabalho também pode estimular a elaboração de mais ações direcionadas à formação docente, especialmente à formação do professor de LI. Afinal, igual às outras licenciaturas, a LI também requer aperfeiçoamento na formação de seus profissionais.

Segundo Nóvoa (2002), a formação do professor se dá ao longo da vida escolar e a aprendizagem da docência ultrapassa o controle de técnicas e metodologias. De acordo com o autor, é inconcebível que para ser professor deva-se levar em consideração apenas o que se aprende na sala de aula da universidade. O licenciando precisa estar inserido em um ambiente palpável, para que então seja um sujeito capaz de agir e decidir com reflexão em situações reais da profissão docente. Posto isto, a formação prática e os cenários de aprendizagem profissional possibilitam a criação de espaços de reflexão, abrindo caminhos para o desenvolvimento integral do letramento acadêmico e da identidade docente do professor iniciante. Esses espaços de reflexão podem ser identificados durante o desenvolvimento da escrita acadêmica. Portanto, seguindo essa linha de pensamento, este estudo realizou uma análise autorreflexiva dos relatórios produzidos por mim ao longo do PRPLI.

\section{Aspectos metodológicos e caracterização da pesquisa}

Nesta pesquisa realizamos a análise de excertos dos relatos reflexivos produzidos durante o período de execução do PRPLI. O objeto de estudo trata-se dos três relatórios elaborados como atividade final de cada semestre do programa. 
O PRPLI foi dividido em cinco etapas, das quais apenas duas interessaram para a nossa pesquisa, quais sejam: ambientação do residente na escola campo e imersão do residente na escola campo. Desta forma, o objeto de estudo também foi dividido em dois momentos, em que para investigar a primeira parte usamos as anotações do diário de campo do relatório I (escrito em LP), produzidos durante o período de observação; enquanto a segunda etapa foi investigada a partir dos diários de campo dos relatórios II e III (escritos em LI), produzidos durante o período de regência.

O trabalho é inserido na área de área da Linguística Aplicada (LA). Conforme descreve Kleiman, Vianna e Grande (2019), a LA apresenta uma definição ampla, pois é um campo que tem interesse por problemas da vida social, investigando questões nas quais a linguagem torna-se o ponto central, o que possibilita o desenvolvimento de tipos variados de pesquisa. Segundo Silva (2015), a LA investiga os problemas da sociedade e da vida humana envolvidos com o uso da linguagem, afirmando ainda que a disciplina atingiu o desenvolvimento necessário para orientar suas abordagens de modo mais amplo. Para o autor:

A linguística aplicada foca na relevância multidisciplinar dos seus resultados. O desenvolvimento de teorias e métodos no campo da linguística aplicada pode contribuir para o encaminhamento de problemas em outros campos e, sobretudo, no próprio campo aplicado. [...] a linguística aplicada reivindica para si um lugar próprio no terreno mais amplo dos estudos da mediação simbólica, rejeitando o lote reservado de "auxiliar da linguística". (SILVA, 2015, p. 3)

Assim, o objeto de pesquisa, bem como as teorias contextualizadas para realizar essa investigação, remetem-nos ao campo de atuação da LA. Nessa perspectiva, os paradigmas teóricos da Linguística permitem que a própria natureza do objeto de estudo aponte para o tipo de pesquisa a ser desenvolvida, afinal a LA está em constante processo de (re)constituição das abordagens de seus objetos de pesquisa (KLEIMAN; VIANNA; GRANDE, 2019).

Entendemos, então, que os padrões teóricos da LA têm muito a agregar à nossa pesquisa. Outrossim, a LA é uma disciplina que trabalha com o conhecimento teórico, e sua aplicabilidade colabora com o desenvolvimento do conhecimento não somente dentro do seu campo de atuação, mas também em outras áreas de investigação (CAVALCANTI, 1986). Por se tratar de uma linha de investigação na qual a Linguística Aplicada se insere, a opção metodológica escolhida para a realização desta análise foi a abordagem qualitativa, uma vez que dentre os mais diversos métodos e técnicas de pesquisa, essa abordagem foi a que mais se adequou ao objeto de estudo deste trabalho. 
A abordagem qualitativa procura obter dados descritivos sobre as pessoas, os lugares, as relações sociais, a interatividade entre o pesquisador e o objeto de pesquisa, bem como busca compreender os fenômenos segundo a perspectiva dos sujeitos envolvidos no estudo (GODOY, 1995). Além do mais, essa abordagem se mostra bastante promissora no âmbito científico e tem ganhado cada vez mais espaço nos últimos tempos (DEZIN; LINCOLIN, 2006).

Segundo Gunter (2006), a pesquisa qualitativa envolve a postura do pesquisador, as estratégias de coleta de dados, o estudo de caso, o papel do sujeito e da aplicabilidade e o uso dos resultados da pesquisa. Vejamos ainda o que diz outro autor sobre a abordagem qualitativa:

[A pesquisa] qualitativa implica uma ênfase sobre as qualidades das entidades e sobre os processos e os significados que não são examinados ou medidos experimentalmente (se é que são medidos de alguma forma) em termos de quantidade, volume, intensidade ou frequência. (DENZIN; LINCOLN, 2006, p. 23)

Portanto, por se tratar de um estudo qualitativo, cujo objeto de investigação consiste na análise de excertos de relatos reflexivos dos três relatórios produzidos durante o período de execução do PRPLI, é certo que a abordagem qualitativa tenha sido a mais indicada.

Quanto ao tipo de pesquisa, utilizamos a de natureza documental, visto que os relatórios serão o nosso objetivo de estudo. Segundo Sá-Silva, Almeida e Guindani (2009, p. 13), “A pesquisa documental é um procedimento metodológico decisivo em ciências humanas e sociais porque a maior parte das fontes escritas - ou não - são quase sempre a base do trabalho de investigação". Em suma, a pesquisa documental é aquela em que a análise dos dados já obtidos ainda não tiveram um tratamento teórico ou que ainda podem ser reelaborados de acordo com os objetos de pesquisa (GIL, 2002). A pesquisa documental é entendida por Severino (2007, p.122) como:

[...] uma fonte de documentos no sentido amplo, ou seja, não só de documentos impressos, mas, sobretudo de outros tipos de documentos, tais como jornais, fotos, filmes, gravações, documentos legais. Nestes casos, os conteúdos dos textos ainda não tiveram nenhum tratamento analítico, são ainda matéria-prima, a partir da qual o pesquisador vai desenvolver sua investigação e análise.

Portanto, a geração de dados provenientes de uma pesquisa documental exige uma leitura e análise atenta do pesquisador. Assim, para esta investigação, considerando que os relatórios de residência foram os documentos estudados, a pesquisa documental foi a mais indicada para o andamento e o aprimoramento deste trabalho. E a partir dos dados gerados 
destes documentos, realizamos uma autorreflexão sobre o processo de formação acadêmica no contexto da Residência Pedagógica.

\section{Autorreflexão no contexto da PRP}

A autorreflexão é a capacidade de refletir sobre si mesmo, retomar o próprio pensamento, isto é, voltar-se para si colocando em questão o que já se conhece sobre si e sobre seus atos. No contexto acadêmico, a autorreflexão permite um olhar crítico-reflexivo para a realidade educacional, possibilitando novas formas de compreender, de aprender e de atuar com mais segurança e efetividade no ambiente pedagógico.

A reflexão sobre a ação é a análise que o indivíduo realiza posteriormente sobre o processo de sua própria ação. Quando utiliza o conhecimento para analisar e avaliar, com reflexões sobre a reconstrução realizada posteriormente, a ação realizada busca compreender e reconstruir sua prática, componente essencial no processo de aprendizagem permanente da formação docente. (ALBUQUERQUE; GONÇALVES, 2019, p.15)

Desse modo, a reflexão é entendida como um processo intencional que permite uma análise crítica de si, de modo a contribuir para a experiência prática dos professores em formação inicial. Assim, o residente analisa o percurso percorrido e reflete sobre ele, gerenciando os próprios comportamentos, pensamentos e sentimentos vivenciados em sala de aula.

Em vista disso, a escrita dos relatórios durante o PRPLI possibilita ao futuro professor refletir sobre suas ações durante a residência. Segundo Carabetta $\operatorname{Jr}$ (2010, p. 581) "a reflexão é vista como a capacidade de voltar para si mesmo". Assim, o autor afirma que o processo da reflexão acontece quando o futuro professor retorna para si, ocorrendo uma autorreflexão, que irá auxiliar na construção de sua identidade profissional. Nas palavras do autor:

A reflexão sobre a ação pode ser considerada uma estratégia importante para a docência, visto que permite encontrar caminhos para o aprimoramento da prática e descobrir acertos e erros do trabalho educacional para construir novos rumos de atuação. (CARABETTA Jr, 2010, p. 582)

Assim sendo, a prática reflexiva oportuniza ao futuro professor os instrumentos capazes de agregar as vivências pessoais ao seu conhecimento profissional de forma acadêmica, facilitando assim a percepção da prática profissional. Por isso, uma vez que lidamos com a realidade das salas de aulas, e os desafios que acompanham todo o processo de ensino e aprendizagem, adquirimos um olhar mais reflexivo sobre o fenômeno da educação. Essa oportunidade de reflexão pode ser encontrada nas experiências registradas nos relatórios 
produzidos durante a residência pedagógica. Por esse motivo, a análise dos relatos reflexivos dos relatórios I, II, III produzidos durante o período de execução do PRPLI são elementos essenciais para identificar o processo de autorreflexão.

Por isso, o edital Capes 06/2018 (BRASIL, 2018) traz como abordagens e ações obrigatórias "a elaboração de relatórios, instrumentos de pesquisa, roteiros e outras atividades oriundas da experiência do residente". Assim, ao registrar as ações desenvolvidas durante a residência, tive a oportunidade de relacionar as experiências pessoais com as acadêmicas, tornando a escrita reflexiva um instrumento por onde pude avaliar meu crescimento e aprendizado.

Nessa perspectiva, a prática reflexiva foi fundamental para meu letramento acadêmico, visto que as expectativas e as experiências vivenciadas ao longo da residência pedagógica foram refletidas nos relatórios. Logo, através desta escrita pude refletir o entrelaçamento da teoria e da prática, e também contribuir com a construção da minha identidade docente.

Então, a autorreflexão no contexto educacional, permite o indivíduo avaliar a si próprio, bem como a relação professor-aluno, uma vez que é um processo contínuo e que deve fazer parte da rotina do ensino do professor, devido à variabilidade pela qual passam os alunos, bem como as constantes deliberações do currículo escolar e as diretrizes educacionais impostas à formação dos educandos (LOPES; MOURA, 2018). Dessa maneira, a escrita reflexiva assume um papel central na formação docente e proporciona o crescimento pessoal e profissional no meio acadêmico. Segundo os autores a autorreflexão:

[...] tem a intenção de possibilitar melhorias e incentivar os alunos a construir e analisar as suas aprendizagens sempre e em cada novo conhecimento. Poderá esse aluno qualificar as suas formas de pensar e definir as suas responsabilidades diante dos resultados obtidos, de forma a construir e reconstruir ideias sobre si mesmos e seu processo de aprendizagem. (LOPES; MOURA, 2018, p. 429)

Assim, o processo autorreflexivo estimula o hábito de se perceber um indivíduo que se autoavalia, e que se conscientiza sobre o que está fazendo e de que forma está fazendo, possibilitando-se localizar as dificuldades e ao mesmo tempo as potencialidades ao longo de seu progresso. Lopes e Moura (2018) afirmam ainda que a autorreflexão possibilita a melhoria na prática pedagógica, no sentido de que este movimento de reflexão se torna mais significativo, uma vez que não se trata apenas de quantidade, mas sim qualidade, isto é, a autorreflexão faz o indivíduo conhecer e mover.

Logo, a autorreflexão evidenciada nos relatórios produzidos por mim ao longo do PRP, promoveram uma autocompreesão sobre minha atuação, pois a partir deles consegui analisar minha própria trajetória e traçar objetivos de aprendizagens. Portanto, os 
procedimentos metodológicos justificados anteriormente auxiliam nossa pesquisa e permitem um estudo mais analítico do material investigado, análise esta que trataremos a seguir.

\section{Escrita autorreflexiva da residente na etapa de ambientação do PRPLI}

Desde sua intitulada obra "Formação de professores e profissão docente", Nóvoa (1992) afirma ser inconcebível separar os aspectos profissionais e pessoais do professor, uma vez que a integração entre eles é essencial para que ele possa atribuir algum sentido a sua formação, a partir de suas experiências pessoais. Dado esse pensamento, a análise autorreflexiva dos relatórios é essencial para esta pesquisa.

Ao longo do PRP foram produzidos três relatórios de residência, no entanto, a análise deste estudo foi dividida em apenas duas partes, as quais apresentam seus respectivos dados a serem investigados: 1) ambientação do residente na escola campo - escrita reflexiva referente ao período de observação (relatório I, em LP); e 2) imersão do residente na escola campo escritas reflexivas referentes ao período de regência (relatórios II e III, em LI). O estudo dos relatórios consistiu em trazer excertos de cada um dos três documentos, e investigá-los de forma a identificar a autorreflexão na escrita desenvolvida durante o PRP, destacando as expectativas, as vivências, as experiências, os sentimentos, entre outros.

As atividades desenvolvidas durante a etapa de ambientação do residente na escola campo proporcionaram um tempo maior de ambientação (60 horas), quando comparado ao estágio obrigatório supervisionado da UFT (20 horas), o que consequentemente contribuiu para uma melhor compreensão dos processos e vivências na escola-campo. Os trechos do relatório destacados ao longo da ambientação variaram entre observações de aulas, planejamentos pedagógicos, participação nas atividades didático-pedagógicas, utilização de instrumentos, entre outros.

O PRP, embora tenha sido elaborado e organizado como um projeto piloto de experimentação (BRASIL, 2018), possibilitou vivências que nos aproximaram da realidade profissional com a qual lidaremos futuramente, além de ampliar nossos referenciais sobre a docência. Segundo Pannuti (2015), as experiências resultantes da residência pedagógica representam uma oportunidade para o residente aprender a integrar seus conhecimentos, articulando-os na prática docente.

Nessa linha de pensamento, tive acesso ao Projeto Político-Pedagógico, ao Regimento

Escolar e a outros documentos pedagógicos da escola. A análise dos mesmos facilitou a 
compreensão dos processos de funcionamento da escola e da sala de aula. Nas melhores oportunidades, também me familiarizei com os diferentes setores da escola, frequentando a secretaria, a orientação e monitoria, a supervisão, a direção e até mesmo a administração financeira, entre outros.

E finalmente observei o trabalho em sala de aula do professor preceptor, cuja atuação me trouxe as primeiras noções práticas da docência no contexto da licenciatura. Participei ainda, dos planejamentos das aulas assistidas e das demais atividades da escola-campo. Assim, durante o período de observação, tive que acompanhar diferentes salas de aula devido a limitada carga horária da disciplina de LI disponibilizada para as turmas das redes de ensino básico do estado do Tocantins. Observei o $6^{\circ}$ e o $9^{\circ}$ anos do ensino fundamental e a $1^{\mathrm{a}}$ e a $2^{\mathrm{a}}$ séries do ensino médio, como também presenciei alguns dias de planejamento pedagógico para completar a carga horária.

Desde o contato com as primeiras turmas soube que presenciaria diversos desafios. Então me compromissei em entender o processo educacional dos alunos como um todo, vivenciando e assimilando situações reais do cotidiano docente. Um dos primeiros desafios que presenciei, relato nos excertos abaixo:

\footnotetext{
No primeiro dia de residência a professora iniciou a aula com o verbo there to be. Ela escreveu no quadro o conceito da matéria iniciada e expôs exemplos com as respectivas traduções. A aula constituiu-se apenas de teoria, a professora escreveu sobre o conteúdo, mas não fez explicações, pois o sinal tocou e não deu tempo de partir para prática. (Excerto (1) - Relatório de residência I $-1^{\circ}$ série do ensino médio)
}

Nos dias de quinta-feira havia somente uma aula de Língua inglesa para a turma observada, $\mathbf{1}^{\circ}$ série do ensino médio. Nos horários em que não havia aula de inglês eu costumava ir para a biblioteca fazer a leitura do Projeto Político Pedagógico do Colégio Estadual Jardim Paulista. Tal documento era razoavelmente grande, então exigia algumas horas de leitura. (Excerto (2) - Relatório de residência I $-1^{\circ}$ série do ensino médio)

Nas duas passagens logo notei uma das maiores dificuldades da disciplina de LI no ensino médio: as turmas tinham apenas uma única aula da disciplina por semana. Devido a essa carga horária limitada, a professora regente não conseguia finalizar o conteúdo, o qual acabava ocupando as aulas seguintes. Ambos os trechos expressam certa quebra de expectativa a partir dessa minha primeira experiência com a realidade do professor de LI, pois vi que uma única aula da disciplina sequer é suficiente para apresentar um conteúdo.

A partir desses dois excertos pude notar um dos principais enfoques da residência pedagógica: as exigências cotidianas do ofício docente no contexto das redes públicas. É o que traz o item 2.1 do edital Brasil (2018): 
[...] A residência pedagógica consiste na imersão planejada e sistemática do aluno de licenciatura em ambiente escolar visando à vivência e experimentação de situações concretas do cotidiano escolar e da sala de aula que depois servirão de objeto de reflexão sobre a articulação entre teoria e prática. Durante e após a imersão o residente deve ser estimulado a refletir e avaliar sobre sua prática e relação com a profissionalização do docente escolar, para registro em relatório e contribuir para a avaliação de socialização de sua experiência como residente. (BRASIL, 2018, p. 18)

Vemos aqui que o programa conseguiu proporcionar a experimentação de situações concretas do cotidiano escolar e de sala de aula. Essa carga horária curta é um dos maiores obstáculos no ensino-aprendizado de LI, e que muitas vezes ainda vem acompanhado por outras realidades, como a falta de professores da área e de recursos didáticos. No entanto, o enfrentamento dessas situações nos traz uma visão mais perspicaz acerca dos problemas característicos da profissão. Para Poladian (2014), a superação desses obstáculos proporciona ao licenciando o desenvolvimento de senso crítico e o aprimoramento das habilidades de um professor reflexivo.

Como mencionado anteriormente, no período de ambientação também procurei me adaptar ao ambiente escolar como um todo, frequentando a sala dos professores na maior parte dos intervalos das aulas. E nos dias de planejamento pedagógico também busquei observar a atuação dos professores, como relato nos excertos a seguir:

O acesso à sala dos professores era livre aos residentes [...]. Esse cenário me possibilitou presenciar os principais assuntos que os professores costumavam debater sobre as turmas onde lecionavam. Nesse dia eles relataram a falta de comprometimento dos alunos com as tarefas escolares devido aos projetos escolares externos que consumiam muito o tempo dos estudantes. (Excerto (3) - Relatório de residência I - Planejamento Escolar)

[...] O diretor inicia a reunião falando sobre o plano de intervenção a ser aplicado ao longo do quarto bimestre. A proposta interventora consiste em um monitoramento da aprendizagem e que a equipe pedagógica seja estimulada para que se alcance os resultados esperados até o final do último bimestre. O plano de intervenção traz as seguintes ações: avaliações dos trabalhos da escola, análise das transferências de alunos, [...] observação dos livros, cadernos e trabalhos de todos os alunos e outras ações similares. (Excerto (4) - Relatório de residência I Planejamento Escolar)

Conforme exponho nos excertos 3 e 4, busco atuar conforme estabelece o Projeto Institucional de Residência Pedagógica da Universidade Federal do Tocantins (PIRP-UFT) (2018), ambientando-me com os diferentes setores da escola, participando de reuniões, seminários e demais atividades na escola-campo, de acordo com a oportunidade. Dessa forma, ao passo que eu frequentava o ambiente dos professores que ali atuavam, tal como participar do planejamento coletivo, as atividades foram se adequando às propostas do programa, que por sua vez, permitiu-me acompanhar de perto as ações pedagógicas inerentes ao fazer 
docente.

Assim, o PRP me proporcionou um vínculo maior com a escola, uma vez que as atividades não foram limitadas simplesmente a observação de aulas. Durante esse período eu também procurava elaborar diagnósticos das turmas que observava e descrevia os aspectos mais significativos. É o que relato nos excertos a seguir:

\begin{abstract}
A segunda série era uma turma razoavelmente pequena, composta com pouco mais de vinte alunos e mais participativa em relação ao primeiro ano. Nessa aula, a professora corrigiu os exercícios que foram passados na aula anterior sobre o uso do pronome impessoal "It". A professora pede que os alunos escrevam as respostas no quadro que depois são corrigidas por ela. (Excerto (5) - Relatório de residência $\mathrm{I}-2^{\circ}$ série do ensino médio)
\end{abstract}

$\mathrm{Na}$ aula desse dia, a professora fez a correção de uma atividade avaliativa com pontuação máxima quatro. Ela pede para que os alunos leiam as perguntas e que em seguida deem suas respostas. A maioria participa da correção e até vibram quando acertam a questão. (Excerto (6) - Relatório de residência $\mathrm{I}-9^{\circ}$ ano ensino fundamental)

O período de observação, a princípio, denota um momento de focar nas estratégias de ensino do professor preceptor, provavelmente porque até então esse é o primeiro contato com a sala de aula, e na condição de residente, é normal buscar em outros professores uma representação de como agir nas aulas. A partir do excerto 6 , no entanto, as observações das aulas acabam mudando de foco, pois passei a observar mais os alunos, em relação ao comportamento, as abordagens mais aceitas por eles, entre outros, haja visto que o feedback dos alunos é um excelente indicativo de que estratégias de ensino adotar.

Tal mudança de foco deve-se à medida que vamos entendendo qual abordagem de ensino adotar, uma vez que são estudadas na universidade, restando ao residente refletir sobre as mais adequadas a usar. Nesta perspectiva, relembro o que Pannuti (2014) afirma, em que é preciso que os alunos possam articular o que aprendem na universidade e o que vivenciam na prática, proporcionando assim, o desenvolvimento da capacidade de relacionar teoria e prática docente.

Dando continuidade à análise, vejo que a participação em eventos de Língua Inglesa, ocorridos na escola-campo, também atendeu à proposta metodológica do PRP referida em Brasil (2018), que diz:

3.1.2 São características essenciais da residência pedagógica:

c) Conduzir o residente a buscar o conhecimento do contexto e cultura da escola, das inter-relações do espaço social escolar, o que compreende conhecer os alunos e relações entre eles, bem como suas condições familiares e outros aspectos considerados relevantes. (BRASIL, 2018, p.18) 
Nessa perspectiva, busquei participar dos eventos da disciplina de LI de forma a compreender a necessidade de tais eventos, assim como observar de que maneira essas circunstâncias afetam e estimulam a aprendizagem da disciplina. No excerto a seguir, relato a participação no evento anual da escola-campo intitulado shopping day:

Uma das professoras preceptoras da residência pediu ajuda para a confecção das "Tags" que foram usadas no "shopping day". Todas as frases usadas nas tags foram retiradas de imagens aleatórias da internet e no geral eram trechos de letras de músicas ou frases engraçadas e criativas. A intenção era de que os alunos pudessem usar as tags para interagir com os demais colegas em Língua Inglesa. (Excerto (7) Relatório de residência $\mathrm{I}-9^{\circ}$ ano ensino fundamental)

Conforme podemos notar nessa última passagem, a residência pedagógica enfatiza esse primeiro momento na escola-campo como um período de observação participante (PALMAS, 2018). Desse modo, pude participar ativamente da execução de projetos e de eventos que já ocorriam na escola. Embora remeta à etapa seguinte, essa observação participante introduz o princípio da imersão. Portanto, a ampliação desse vínculo, de forma a participar de tais eventos como o shopping day, me permitiu um maior comprometimento com as atividades didático-pedagógicas da escola-campo, agregando ainda, neste contexto, mais que apenas valores pedagógicos, mas também sociais e culturais.

Como mencionado anteriormente, também observei os diferentes setores da escola. E seguindo a proposta do PRP em Brasil (2018), que recomenda ao residente compreender os processos e instrumentos pedagógicos da escola e da sala de aula, busquei conhecer de perto o trabalho da orientação pedagógica, como descrevo no excerto abaixo:

\begin{abstract}
A professora preceptora pede à responsável pela Orientação Pedagógica que mostre como é feito o processo de orientação diante dos alunos indisciplinados. O trabalho dela é basicamente conscientizar e aplicar aos alunos as consequências de um mau comportamento os quais variam de uma simples advertência a uma transferência de escola. Segundo ela, a maioria dos casos são reversíveis. A orientação pedagógica também conta com um trabalho de visita na casa dos pais dos alunos e atualmente tem o apoio do setor financeiro da instituição para fazer doações às famílias mais carentes dos estudantes. (Excerto (8) - Relatório de residência I Orientação Pedagógica)
\end{abstract}

Assim, entendi que a orientação pedagógica é um dos setores mais importantes da escola, porém tem menos visibilidade que os demais. Concluí, também, que os procedimentos realizados pela orientação são de suma importância para a comunidade. Além de desenvolver propostas de intervenção de maneira articulada com a equipe pedagógica para conhecer e lidar com o comportamento dos alunos, levando-os a refletir sobre atitudes inadequadas para o ambiente escolar, o setor também é responsável pela assistência às famílias carentes dos 
estudantes, realizando trabalhos de doação e outras ações que diminuem os riscos de evasão escolar.

Observar o trabalho da orientação me permitiu um olhar mais aprofundado sobre a importância da comunidade escolar e os sujeitos ao seu redor. Assim, a orientação me auxiliou na ambientação também com a comunidade em torno da escola, no que se refere a conhecer os sujeitos que ali residem e de como as condições de vida deles influenciam no aprendizado e na frequência às aulas. Tal reflexão retoma o pensamento de Nóvoa (1992), em que o ponto de vista individual não deve ser o único elemento da formação dos licenciandos. Desta maneira, conhecer e acompanhar a orientação pedagógica de perto, desmistificou a ideia do professor da orientação como um mero aconselhador pedagógico.

Além de conhecer os diferentes setores da escola-campo, também tive contato com alguns dos instrumentos de trabalho usados pelos professores. No excerto a seguir, relato a experiência com o sistema de gerenciamento de notas apresentado pela professora preceptora.

\footnotetext{
Nesse dia a professora preceptora apresentou o sistema de lançamento de notas e de que forma é feita a anotação das atividades avaliativas e extracurriculares. No entanto, o sistema havia caído nesse dia, então o registro das notas foi feito manualmente em planilhas do Excel para depois serem transferidas para o programa de notas. As notas se dividiam em lista de exercícios, "visto" no caderno e avaliação. (Excerto (9) - Relatório de residência I - Diário de notas)
}

Conhecer e operar o sistema de gestão de notas escolar foi mais uma das atividades de observação participante no período de ambientação. Atividades como essas agregaram mais significado à formação docente, pois conhecer tais instrumentos me fez compreender as dificuldades e as principais demandas que os professores têm para poder realizar seu trabalho de forma eficiente.

O período de ambientação, embora mais curto que o de imersão, é essencial para o residente obter, a princípio, uma melhor compreensão do fenômeno e dos processos educativos, bem como começar a desenvolver a competência do fazer docente, atuação essa que é aperfeiçoada no período da regência, tema do nosso próximo tópico.

\section{Imersão do residente na escola campo}

A imersão do residente na escola campo constituiu a terceira etapa do PRPLI, sendo executada através da regência em sala de aula. Para estudar essa etapa fizemos a análise de trechos dos relatórios de residência II e III de forma a colaborar com a autorreflexão realizada nesta pesquisa. 
Durante este período, lecionei em outras turmas, tanto do ensino fundamental quanto do ensino médio. Além da atuação em sala de aula, o período de imersão se constituiu em planejamento e realização de intervenções pedagógicas, articulando a teoria e a prática, de modo que tais ações ampliaram a noção de conhecimento pedagógico, de conteúdo curricular, entre outras ações inerentes ao fazer docente, conforme proposto pelo PIRP-UFT (2018).

Nesses meus relatórios exponho minha vivência durante a imersão em sala de aula, de forma a expandir as experiências anteriores, ou seja, desenvolvo reflexões que englobam todas as etapas da residência, articulando-as às especificidades do ensino. Para Giglio e Lugli (2013, p. 65) imersão é “[...] o vínculo do residente com as escolas-campo de forma intensa, sistêmica e por um período limitado." O programa trata a imersão como elemento essencial para assimilar a realidade escolar. Seguindo essa linha de pensamento, reflito a seguir:

\begin{abstract}
A primeira coisa que pensei nessa residência foi que a maioria dos alunos não gosta da língua inglesa e isso me causou muito medo, pois deveria ensinar a todos, embora tivesse que enfrentar muitos desafios. [...] O segundo pensamento foi refletir sobre eu estar preparada para lidar com o processo de ensino-aprendizagem, se minha interação com os alunos permitiria que eles aprendessem, e se eu teria uma boa didática. Confesso que alguns desses questionamentos me assustaram, então vi que era melhor deixar as respostas fluírem de acordo com o andamento da minha residência. (Excerto (10) - Relatório de residência II - Período de imersão)
\end{abstract}

Nessa primeira passagem relato minhas hesitações antes mesmo de iniciar a regência em sala de aula. Embora o período de observação auxilie muito a ingressar na próxima etapa, a regência contém suas especificidades e seus desafios, os quais até então apenas observava, mas que agora seriam enfrentados totalmente por mim.

Assim, notei que a regência me possibilitaria refletir e analisar minha própria prática enquanto residente. Em Palmas (2018), é um dos objetivos específicos da residência: desenvolver coletivamente projetos, práticas pedagógicas criativas e inovadoras para o enfrentamento dos desafios e alcance da finalidade da educação escolar, possibilitando ao residente um pensar global de modo a permitir que o mesmo faça reflexões críticas sobre a escola-campo, os seus sujeitos e os desafios de ensino. Com esse objetivo em mente, comecei a simplificar minhas primeiras hesitações e passei a refletir sobre o verdadeiro sentido de ensinar, em que relato:

Quando iniciei a residência observei que as turmas tinham perfis distintos, porém em todas existe uma boa quantidade de alunos que se interessaram pelo assunto e mostraram realmente vontade de aprender. Isso me deixou mais animada porque, embora fosse um número pequeno de alunos interessados, comecei a ter mais confiança e ser positiva em relação a minha residência. Também encontrei alunos desmotivados ao extremo, independentemente da matéria ensinada. Esses alunos foram os mais difíceis de lidar, então eu vi a necessidade de buscar formas diferentes de despertar o interesse nesses alunos, até hoje não consegui atingir esse objetivo de forma plena, mas percebo uma 
boa diferença em relação ao início, eu acredito que é um "trabalho de formiga". (Excerto (11) - Relatório de residência II - Período de imersão)

No excerto 11, exponho uma de minhas primeiras ações, que foi tentar desenhar um perfil das turmas em que lecionava. Dessa forma, pude avaliar quais posturas adotar para melhorar a minha segurança em sala de aula e ao mesmo tempo promover a aprendizagem, mesmo para os alunos que não se interessavam pela LI. Tal estratégia remete a uma das primeiras atividades que aprendi durante a observação participante em que, segundo um dos objetivos elencados em Palmas (2018), o residente deve elaborar diagnósticos ao longo do PRP, realizando uma avaliação qualitativa sobre como fazer o ensino e a aprendizagem, registrando todos os apontamentos em cadernos de campo.

Assim, desde as minhas primeiras regências, busquei refletir sobre o que era ensinado na universidade, e de que modo eu poderia articular esse aprendizado ao contexto da escolacampo. Procurei, também, destacar os aspectos mais significativos durante meus registros, uma vez que tais anotações me despertavam um olhar mais reflexivo sobre o que eu poderia fazer de diferente para melhorar o desempenho dos meus alunos. É o que relato a seguir:

\begin{abstract}
Quando comecei a planejar as aulas vi a necessidade de começar a observar o nível de habilidade comunicativa dos meus alunos, pois eu poderia planejar as aulas e ajudá-los em suas maiores dificuldades. Na escola Jardim Paulista, eles parecem não se concentrar especificamente em uma habilidade única linguística, o que é interessante porque os professores têm mais liberdade para trabalhar as habilidades comunicativas menos desenvolvidas de seus alunos. E acredito também que isso permite um fortalecimento da relação entre professor e aluno, uma vez que ele conhece as dificuldades de seus alunos, poderá desenvolver melhores estratégias para trabalhar com eles. (Excerto (12) - Relatório de residência II Período de imersão)
\end{abstract}

De acordo com esse relato, referencio mais uma vez um dos objetivos específicos do projeto institucional da residência, cuja finalidade também é proporcionar ao residente o desenvolvimento das habilidades e competências para planejamento individual e coletivo na escola e na universidade (PALMAS, 2018). Assim, conforme observamos no excerto 12, o planejamento das aulas era flexível, pois o preceptor me dava liberdade de abordar outras habilidades comunicativas, além daquelas discutidas nos planejamentos coletivos.

Nos próximos excertos descrevo ainda sobre o trabalho com as habilidades comunicativas na disciplina de LI. Exponho essa questão com bastante clareza, porque a identifiquei como um dos maiores desafios enfrentados durante a imersão, período em que melhor desenvolvi minha capacidade de identificar problemas inerentes à prática educativa, como aponto nos excertos 13 e 14. Tal experiência também constitui uma das propostas relacionadas nos objetivos específicos do PRP em Palmas (2018). 
Quanto às atividades de escuta, ainda apresentam pouca afinidade com essa habilidade comunicativa. Tenho tentado trabalhar essa habilidade junto com as demais. Assim, sempre que possível, procuro fazer atividades que envolvam pelo menos duas das quatro competências linguísticas. Nesse caso, trabalhei a escuta junto com a leitura. Acredito que estes sejam os mais difíceis para eles principalmente porque eram muito pouco desenvolvidos até então. (Excerto (13) Relatório de residência II - Período de imersão)

Até o final da minha residência acredito que eles ainda irão melhorar muito suas habilidades comunicativas e farei o possível para que isso aconteça. Em todas as quatro turmas em que realizei minha residência, procurei despertar o entusiasmo em todos os meus alunos. Havia aulas de que gostavam e outras de que não gostavam, mas todas me serviram de experiência. (Excerto (14) - Relatório de residência II - Período de imersão)

Assim, me orientei pelos referenciais teórico-metodológicos sobre como trabalhar as habilidades comunicativas, os quais foram vistos em sala de aula na universidade. Busquei compreender as causas e consequências dos principais desafios que ia encontrando, além de escolher as melhores alternativas para solucioná-los (PALMAS, 2018), conforme menciono no excerto 13, em que para desenvolver tal conteúdo, procurei trabalhar duas habilidades comunicativas ao mesmo tempo, pois parecia ser mais eficiente.

Nos planejamentos das aulas também procurava destacar aspectos da BNCC segundo a sequência didática permitia, uma vez que a própria residência traz a vinculação à BNCC como uma das abordagens obrigatórias do programa, conforme as diretrizes do edital Brasil (2018).

2.1 O Programa de Residência Pedagógica visa [...] promover a adequação dos currículos e propostas pedagógicas dos cursos de formação inicial de professores da educação básica às orientações da Base Nacional Comum Curricular (BNCC). (BRASIL, 2018, p. 01)

Portanto, as experiências relatadas no relatório II abrangem os primeiros momentos da imersão na escola campo. Ao longo desse período, procurei ajustar minha prática às propostas da residência pedagógica, desde as ações e as abordagens obrigatórias elencadas no edital Brasil (2018), quanto aos objetivos gerais e específicos propostos pelo PIRP- UFT.

Como foi esclarecido anteriormente, os documentos da análise constituem-se em três relatórios. Passemos então a analisar trechos do último relato reflexivo que também foi produzido a partir da imersão projetada pela residência. Durante esse período, ainda estive atuando em sala de aula e participando das demais atividades da escola-campo. Ao longo do registro das anotações procurei destacar aspectos diferentes dos que havia apontado no relatório anterior, como por exemplo, reflito adiante sobre a regência ter acontecido em parceria com outro residente. 


\begin{abstract}
Como a regência das aulas é uma ação que não poderia ser realizada por nós duas ao mesmo tempo, eu e minha companheira de residência nos revezávamos ensinando, quando não fosse a vez de uma, a outra estaria auxiliando nas atividades propostas pela colega. Como a regência das aulas é uma ação que não poderia ser realizada por nós duas ao mesmo tempo, eu e minha companheira de residência nos revezávamos ensinando, quando não fosse a vez de uma, a outra estaria auxiliando nas atividades propostas pela colega. Este revezamento foi fundamental porque podíamos nos auxiliar e ao mesmo tempo ajudar os alunos nas atividades que eles apresentavam dificuldades, bem como tentar observar o que cada uma poderia mudar observando como a outra ensinava. (Excerto (15) - Relatório de residência III - Período de imersão)
\end{abstract}

As regências sempre eram praticadas em dupla. Enquanto uma lecionava, a outra auxiliava os alunos que tinham mais dificuldade. Essa estratégia nos trazia mais segurança em sala de aula, pois na maioria das vezes a preceptora dava liberdade aos residentes, dando assistência apenas quando solicitada. Para Pannuti (2014), é essencial o estabelecimento de um espaço de formação de professores que possibilite a troca de experiências entre os futuros profissionais, e o PRPLI potencializou essa necessidade ao propor que as regências e as confecções de relatórios fossem feitas mediante parcerias.

Embora o fazer docente seja um ato individual, enquanto o professor se torna a figura de maior autoridade na sala de aula, a residência nos proporcionou momentos de valorização do planejamento e da atuação em coletivo. Portanto, ao atuar em parceria, pudemos nos espelhar no nosso colega, que assim como eu estava em formação, e cada um pôde aprender com o outro a exercer outras funções em sala de aula. Relato ainda brevemente sobre essa parceria no excerto a seguir:

\footnotetext{
Nos primeiros planos de aula, minha companheira de residência e eu procuramos acompanhar o conteúdo programático das aulas, buscando sempre articulá-lo com o que aprendíamos na universidade. Um dos principais documentos estudados no curso foram os Parâmetros Curriculares Nacionais do Ensino Médio (PCNEM), que segue: "É, portanto, imprescindível conferir ao ensino escolar de língua estrangeira um caráter que, além de capacitar o aluno a compreender e produzir enunciados corretos no novo idioma, proporcione ao aprendiz atingir um nível de competência linguística capaz de permitir lhe dar acesso a informações de diversos tipos, ao mesmo tempo que contribuem para a sua formação geral enquanto cidadão." (BRASIL, 2000, p. 26) (Excerto (16) - Relatório de residência III Período de imersão)
}

No excerto 16 também menciono sobre um dos documentos visto em sala de aula na universidade, os Parâmetros Curriculares Nacionais do Ensino Médio. Como podemos observar, procurei em todos os momentos articular a teoria com a prática para facilitar minha atuação em aula, uma vez que a residência propõe um estreitamento entre os saberes discutidos nos cursos de licenciaturas com o contexto das práticas e das atividades das escolas-campo (BRASIL, 2018). 
Além de buscar esse entrelaçamento entre teoria e prática, também tive que lidar com situações cotidianas da escola onde atuava. No excerto a seguir descrevo uma dessas situações e como isso afetava meus planejamentos.

No início do terceiro semestre, [...] ficávamos praticamente com duas turmas fixas, uma do Ensino Fundamental, sétimo ano, e uma do Ensino Médio, terceira série, mas antes do final desse semestre, havia mudanças constantes no horários das disciplinas que afetavam tanto nas trocas dos horários como também nas mudanças de classes. E isso acontecia semanalmente. (Excerto (17) - Relatório de residência III - Período de imersão)

[...] Então todas as semanas tínhamos o trabalho de planejar uma aula e depois deixar de ministrar, porque as mudanças de aulas e horários eram constantes. Quando questionava sobre o porquê dessas inúmeras mudanças, nossa preceptora explicava que isso era normal no ambiente escolar, pois muitas vezes a escola tinha que mudar os horários das turmas para cumprir o horário exigido por alguns professores, afinal alguns deles trabalhavam em outras escolas [... ] (Excerto (18) Relatório de residência III - Período de imersão)

Com a residência, pude adquirir aprendizagens significativas por meio da imersão na escola-campo. Conforme as passagens 17 e 18, relato sobre as dificuldades em seguir meus planejamentos de aulas devido às constantes trocas de horários e turmas onde lecionava. Tal situação me fez conhecer as particularidades da escola onde atuava, além de me estimular a vislumbrar alternativas de solução para esses problemas. Além do mais, as regências foram adquirindo mais eficiência no sentido de se prever e identificar situações-problemas no contexto escolar, possibilitando-me desenvolver formas de enfrentamento ou superação dos problemas.

Quanto às ações de intervenção, o PIRP-UFT (2018, p. 20) propôs a "Elaboração de planos de intervenção baseados na análise das demandas da escola [...], bem como dos conteúdos escolares e as metodologias inovadoras articuladas a BCCN". Trago a seguir trechos sobre a atividade de intervenção pedagógica da qual participei no quarto bimestre da escola.

Durante o quarto bimestre também participamos de vários eventos escolares de língua inglesa, incluindo nós e outros alunos de graduação. Auxiliamos na organização de um desses eventos: O English Music Festival. O Festival de Música Inglesa foi uma iniciativa da nossa preceptora, contando com a parceria da escola e demais profissionais da instituição. Diversos alunos compareceram ao festival, para o qual inclusive constituiu-se uma banca julgadora para eleger as melhores atuações, além de atribuir prêmios. (Excerto (19) - Relato Relatório de residência III - Período de imersão)

Notamos que os alunos têm o hábito de comparecer aos eventos de inglês da escola, mesmo aqueles que demonstram não gostar da disciplina. Observamos, no entanto, que essa participação não se deu apenas pelo fato da atribuição de notas, mas também porque os alunos apresentam menos resistência em aprender inglês quando estão em um contexto diferente do da sala de aula. No caso do festival de música, por exemplo, os alunos participaram de forma mais 
compromissada com as atividades cobradas no evento, bem como demonstraram interesse em expor seus trabalhos ou simplesmente apreciar a apresentação do colega. Nesse sentido vale ressaltar o que diz o PCN + Ensino Médio, no que se refere aos diferentes contextos de aprendizagem:

O desenvolvimento das competências discursiva, gramatical e sociolinguística só irá ocorrer de maneira adequada se todo o trabalho com língua estrangeira for feito de forma contextualizada, por meio de atividades diversificadas, intencionais e sistemáticas, que levem em conta o conhecimento trazido pelo aluno bem como seus interesses e dificuldades, especialmente em se tratando de classes grandes e heterogêneas. (BRASIL, 2000, p. 121) (Excerto (20) - Relatório de residência III Período de imersão)

De acordo com o proposto pelo programa, participei da realização de projetos didáticos envolvendo a LI para o ensino de conteúdos e de atividades. Nos trechos anteriores, excertos 19 e 20, descrevo sobre a intervenção pedagógica que vivenciei durante a residência, que foi um dos eventos dos quais participei, desde a organização à checagem de desempenho dos alunos. A realização dessas atividades criativas e inovadoras promoveu um maior engajamento com as turmas onde lecionava, pois ao final de cada projeto eu refletia como essa socialização melhorava o desempenho dos alunos e a minha atuação em sala de aula. A partir dessa reflexão, procuro ponderar sobre os outros períodos, relatando:

Ao analisar todas as fases da residência, observação e regência, percebemos que os alunos criaram aceitação pela língua inglesa através dos diferentes recursos que utilizamos na hora do ensino. Em relação às habilidades comunicativas, também notamos muitas vezes estranheza por parte dos alunos quando decidíamos abordar outras habilidades comunicativas nas quais eles não tinham o hábito de praticar. (Excerto (21) - Relatório de residência III - Período de imersão)

Nesse momento, procuro refletir sobre o que as experiências que vivenciei no período de observação têm em comum com o que experimentei durante a regência. Finalmente, cheguei à conclusão de que o interesse dos alunos pela LI aumentava de acordo com os recursos didáticos que eu apresentava em sala de aula, seja um game, um equipamento audiovisual, uma dinâmica, enfim, qualquer instrumento que não se reduzisse apenas ao quadro ou somente a um livro. Nóvoa (2002) pondera que a formação do professor se dá ao longo da vida escolar e a aprendizagem da docência ultrapassa o controle de técnicas e metodologias. Portanto, estar inserida no ambiente escolar repleto de situações reais da profissão, permitiu-me desenvolver a capacidade de agir e decidir com reflexão.

Também nessa mesma passagem (excerto 21), reflito sobre as habilidades comunicativas que trabalhei durante toda a regência. Nos conteúdos programáticos de algumas turmas, a sequência didática da disciplina trabalhava apenas uma ou no máximo duas habilidades comunicativas. 


\begin{abstract}
Nas outras habilidades, principalmente conversação e leitura, tive mais dificuldade para trabalhar com os alunos, principalmente na turma do terceiro ano do Ensino Médio, pois nas aulas que eu ministrava os alunos eram mais resistentes para falar ou ler em voz alta. Por isso procurei mecanismos que me ajudassem a incentivar os alunos a falar inglês, mesmo que respondessem pelo menos à chamada, pedindo-lhes que respondessem Presente!, Estou aqui! ou Aqui!, e sempre tentando elogiar quando usavam uma dessas frases dizendo Muito bom! ou Ótimo!. Ou simplesmente tentava iniciar uma conversa com eles aleatoriamente usando frases que eles conheciam, perguntando Como você está? Bem? Mal? Mais ou menos? ou $O$ que você vai fazer no final de semana? Estudar, assistir a um filme ou dormir... (Excerto (22) - Relatório de residência III - $3^{\circ}$ série do ensino médio)
\end{abstract}

No excerto 22, trago ainda uma reflexão sobre o aprendizado das habilidades comunicativas. Na turma 33.01, que foi a classe em que mais estive lecionando, busquei me adequar às particularidades da turma, adotando uma postura mais espontânea por estar lidando com adolescentes com alto nível de retraimento quando da prática das habilidades de comunicação. Essa postura reflete o enfoque das teorias estudadas na universidade, pois procurei reforçar o ensino de LI como uma experiência proveitosa e não frustrante, em que a LI possa de fato ser aprendida nas escolas (BRASIL, 2000).

Durante a regência, em geral, desenvolvi ações e estratégias que me permitiram maior aproximação com os alunos, entendendo suas maiores dificuldades e quais desafios deveríamos enfrentar juntos. Assim, através dessa vivência, a imersão na escola-campo colaborou de forma ampla para minhas articulações entre teoria e prática, além de contribuir com a construção da minha identidade docente. Nóvoa (1992) afirma que é fundamental o professor refletir sobre suas experiências para que não seja apenas um depositário de informações, visto que estas por si só não amparam a experimentação. Por isso, compreendi a relevância da escrita reflexiva no contexto do PRPLI nesse meu processo de formação, especialmente porque pude desenvolver esta pesquisa.

Por fim, através da escrita dos três relatórios do PRPLI, refleti sobre a importância do trabalho docente e todos os seus desdobramentos. A residência pedagógica promoveu todo esse processo, visto que esse aprendizado ainda será necessário futuramente quando me deparar com as exigências cotidianas da docência nas redes de ensino. Portanto, ao vivenciar o programa, entendi a necessidade de tais ações voltadas para este contexto, e também consegui melhorar minha escrita acadêmica, conferindo a esta um caráter crítico-reflexivo. E finalmente pude desenvolver este trabalho autorreflexivo, o qual concluo a seguir.

\title{
Conclusão
}


A residência pedagógica foi uma experiência inédita para a UFT, e para mim enquanto professora em formação. Assim, por meio deste trabalho, pude destacar a importância da autorreflexão identificada nos relatórios de residência, evidenciando as contribuições da escrita reflexiva desenvolvida durante o PRP e a relevância das ações oriundas deste para a formação docente. Entendo que tais objetivos foram alcançados a partir da análise dos meus relatórios produzidos ao longo do programa. Destarte, a escrita autorreflexiva no contexto do PRPLI pode contribuir para a formação do futuro docente.

Quanto às etapas do programa discutidas nesta pesquisa, concluímos que as propostas, em geral, foram atendidas e efetivadas conforme estava ao meu alcance. Ambas as etapas proporcionaram experiências produtivas tanto aos residentes quanto aos preceptores. E embora o PRP tenha trazido como foco o residente, não pude deixar de notar que o professor preceptor também usufruiu de momentos de aprendizagem: o curso de formação de professores preceptores, a avaliação e a socialização da residência por meio de reuniões e seminários acadêmicos, as intervenções pedagógicas que trouxeram melhoria para a escolacampo.

A fase de ambientação de imediato aumentou as possibilidades de minha atuação como professora. Logo percebi que apenas observar aulas de outros professores não integraliza o processo de formação docente, como também deve-se adotar uma postura mais ativa, conforme a observação participante estabelecida pelo PRP. Essa ação foi mais desenvolvida quando passei a conhecer melhor todos os setores da escola. Em especial, destaquei a orientação pedagógica, por perceber a importância de seu papel para a comunidade escolar num todo.

Durante a escrita do primeiro relatório, refleti sobre as expectativas e as necessidades das redes de ensino. Embora esta tenha sido a segunda fase de execução do programa, a ambientação me despertou um olhar mais elaborado quando comparado ao que eu idealizava na universidade até então. E ao observar o trabalho do professor preceptor, pude presenciar a diferença entre a escolha de técnicas de ensino, didáticas e metodologias. Vi essa oportunidade como uma forma de materialização do que aprendi no âmbito da universidade, e que certamente influenciou na minha postura durante a regência. O preceptor, na qualidade de sujeito mediador entre residente e professor orientador, trouxe um nivelamento entre essas duas figuras integrantes do programa, promovendo uma conversação síncrona e desprovida de hierarquia. Por isso, a importância do preceptor no processo de ensino-aprendizagem. 
Quanto à escrita durante esse período de ambientação, notei que a mesma possuía um caráter mais descritivo do que reflexivo, sendo aperfeiçoada progressivamente nos outros relatórios. Ao reler o relatório I, pude me autoavaliar sobre "o que" e "como" eu deveria registrar as minhas observações, o que me estimulou a escrever melhor nas etapas posteriores. Um elemento muito importante para essa evolução deve-se também à socialização desses registros com os demais residentes, preceptores e orientadores, pois tal conversação me incentivou a trazer mais reflexão do que apenas uma descrição das atividades.

A etapa de imersão, por sua vez, conferiu um maior tempo de vinculação com a escola-campo. Vivenciei os processos de gestão e ensino da escola de modo geral, cuja compreensão dos mesmos facilitou o início da minha atuação em sala de aula. Dessa maneira, as atividades de regências foram planejadas a partir do diagnóstico elaborado no processo de ambientação. Nesse contexto ainda, aprendi a tomar decisões coletivas, fruto dos encontros quinzenais entre docente orientador, preceptores e demais residentes, pois a troca de ideias durante esses momentos de socialização tornou minha atuação mais segura.

Sobre a orientação e o acompanhamento do professor durante a regência, reitero, mais uma vez, a importância do preceptor no processo de ensino-aprendizagem. Tal supervisão me instigou a ter um olhar mais apurado em relação à realidade sociocultural dos alunos, assim como seus níveis de aprendizado. E embora os preceptores constituíssem um nível de profissionalização, estabeleceu-se uma parceria, isto é, um nivelamento da equipe, o que permitiu a construção de aprendizagens que fizeram sentido para mim enquanto futura docente.

Quanto às escritas durante o período de regência, concluí que elas evoluíram bastante, quando comparadas aos primeiros registros. Percebo que os relatórios adquiriam um caráter mais crítico e reflexivo, especialmente quando tive de lidar com problemas cotidianos da escola-campo. As escritas, de um modo geral, revelam que durante minha atuação tentei identificar o que estava bom, e o que estava ao meu alcance para melhorar.

Entendi que a profissão professor(a) denota um trabalho de resiliência, e que dificuldades como falta de recursos didáticos, carga horária pequena, horários com mudanças constantes, enfim, fazem parte da realidade escolar. Entretanto, tais adversidades nos tornam mais pacientes e cientes de que para o fazer docente não existe uma "receita ideal", mas sim a persecução de uma educação de qualidade que melhore a vida de nossos alunos a partir da comunidade escolar. Dessa forma, todas as atividades de imersão realizadas durante o 
programa me estimularam a refletir sobre e avaliar minha prática -docente, a qual pude desenvolver tanto acadêmica quanto profissionalmente.

A partir das minhas escritas e com base na autorreflexão, concluímos que a participação no PRPLI foi significativa para minha formação, visto que ao longo dos relatórios pude avaliar a contribuição dessas ações para a autorreflexão. Por fim, entendi realmente a importância do programa no meu letramento acadêmico e no meu crescimento profissional, enquanto futura professora de LI. E que com este trabalho posso validar a necessidade do desenvolvimento de mais ações no contexto da formação de professores, porque através das experiências vivenciadas no programa, pude enfim desenvolver minha identidade profissional.

\section{Referências}

ALBUQUERQUE, Andréa Souza de; GONÇALVES, Tadeu Oliver. Os desafios de ser e estar na profissão docente: reflexões de uma professora sobre sua trajetória profissional. Revista Brasileira de Pesquisa (Auto)Biográfica, Salvador, v. 04, n 10, p. 123-140, jan./abr. 2019.

BRASIL. Base Nacional Comum Curricular (BNCC). Brasília: MEC. 2017. Disponível em:<http://basenacionalcomum.mec.gov.br/images/BNCC_20dez_site.pdf > Acesso em 20 out. 2019.

Edital CAPES 06/2018 que dispõe sobre a Residência Pedagógica. Disponível em:<https://www.capes.gov.br/images/stories/download/editais/01032018-Edital6-2018-residencia-pedagogica.pdf >. Acesso em 25 out. 2019.

Parâmetros curriculares nacionais (PCNs). Terceiro e quarto ciclos do ensino fundamental. Língua Estrangeira. Brasília: MEC/SEF, 2000.

CARABETTA Jr., Valter. Rever, Pensar e (Re)significar: a importância da reflexão sobre a prática na profissão docente. Revista Brasileira de Educação Médica. SP: 2010.

CAVALCANTI, Marilda do Couto. A propósito da Linguística Aplicada. Trabalhos de Linguística Aplicada, n.7, p. 5-12, 1986.

DENZIN, Norman; LINCOLN, Yvonna. A disciplina e a prática da pesquisa qualitativa. 2006. Disponível em: < https://pt.scribd.com/document/118314959/A-disciplina-e-a-praticada-pesquisa-qualitativa >. Acesso em: 18 mai. 2020.

GIGLIO, Celia Maria Benedicto; LUGLI, Rosario Silvana Genta. Diálogos pertinentes na formação inicial e continuada de professores e gestores escolares. A concepção do Programa de Residência Pedagógica na UNIFESP. (2013) Disponível em: <https://periodicos.ufpel.edu.br/ojs2/index.php/caduc/article/view/4173>.Acesso em 07 nov. 2019. 
GIL, Antônio Carlos. Como elaborar Projetos de Pesquisa. São Paulo: Atlas, 2002.

GODOY, Arllda Schmidt. Introdução à pesquisa qualitativa e suas possibilidades. Revista de Administração de Empresas, São Paulo, v. 35, n. 2, p. 57-63, mar./abr. 1995.

GÜNTHER, Hartmut. Pesquisa qualitativa versus pesquisa quantitativa: esta é a questão? Psicologia: Teoria e Pesquisa, Brasília, v. 22, n. 2, p. 201-210, mai./ago. 2006.

KLEIMAN, Angela Bustos.; VIANNA, Carolina Assis Dias; GRANDE, Paula Baracat de. A Linguística Aplicada na contemporaneidade: uma narrativa de continuidades na transformação. Calidoscópio, São Leopoldo, v. 17, n. 4, p. 724-742, dez. 2019.

LOPES, Maria Dolores Ferreira; MOURA, Éliton Meireles de. A autoavaliação na construção de uma prática docente de qualidade. Diversa Prática, Uberlândia, v. 5, n.2, p.419-444, $2^{\circ}$ semestre 2018.

NÓVOA, Antônio. Os professores e a sua formação. Lisboa: Dom Quixote, 1992.

Formação de professores e trabalho pedagógico. Lisboa: Educa, 2002.

PALMAS. A Residência Pedagógica e formação docente na UFT: projetos, metodologias e práticas pedagógicas que articula teoria e prática, ensino superior e educação básica no Estado do Tocantins. Palmas: UFT, 2018.

PANNUTI, Maísa Pereira. A relação teoria e prática na residência pedagógica. 2015. (Relatório de pesquisa).

POLADIAN, Marina Lopes Pedrosa. Estudo sobre o programa de residência pedagógica da Unifesp: uma aproximação entre universidade e escola. Disponível em: <http://www.uece.br/endipe2014/ebooks/livro2/ESTUDO\%20SOBRE\%20O\%20PROGRAM A\% 20DE\%20RESID $\%$ C3\%8ANCIA $\% 20$ PEDAG\%C3\%93GICA\%20DA\%20UNIFESP\%20 UMA $\% 20 A P R O X I M A \% C 3 \% 87 \%$ C3\%83O\%20ENTRE\%20UNIVERSIDADE\%20E\%20ES COLA.pdf>. Acesso em 03 nov. 2019.

SEVERINO, Antônio Joaquim. Metodologia do trabalho científico. 23. ed. rev. e atual. São Paulo: Cortez, 2007.

SÁ-SILVA, Jackson Ronie; ALMEIDA, Cristovão Domingos de; GUINDANI, Joel Felipe. Pesquisa documental: pistas teóricas e metodológicas. Revista Brasileira de História \& Ciências Sociais. Ano I - Número I -Julho de 2009.

SILVA, Daniel do Nascimento e. 'A propósito de Linguística Aplicada' 30 anos depois: quatro truísmos correntes e quatro desafios. Delta, São Paulo, v.31, n.spe, p.349-376, 2015. 